\title{
O SENTIDO DE LAR NA PRODUÇÃO DE HABITAÇÃO SOCIAL: ESTUDO NO TABOQUINHA
}

\author{
AMPUERO, Nayra Gomes Souza \\ Universidade Federal do Pará, e-mail: nayampuero@gmail.com \\ PERDIGÃO, Ana Klaudia de Almeida Viana \\ Universidade Federal do Pará, e-mail: klaudiaufpa@gmail.com
}

\begin{abstract}
RESUMO
Investiga-se a produção de habitação social e o conceito lar, objetivando levantar o sentido de lar em situações de remanejamento/reassentamento habitacional na Amazônia, considerandose aspectos significativos e marcadamente referenciados no espaço físico, associados aos aspectos subjetivos do habitar para o morador e complementando a interpretação do espaço construído sob o olhar dos técnicos envolvidos na execução da política no reassentamento habitacional proposto no Projeto Taboquinha, Belém-Pará. Adotou-se como metodologia, a pesquisa do tipo qualitativa, com abordagem multimétodos, utilizando a pesquisa de campo com coleta de dados, através da aplicação de questionários, mapeamento visual e entrevistas com os moradores. Os resultados apontam a presença do sentido de lar pelos moradores quando dizem que sentem falta de algo relacionado a aspectos subjetivos, ou costumes, valores afetivos. Como contribuição, os resultados promovem uma discussão profícua entre os diferentes agentes envolvidos na produção habitacional, apoiando-se em base mais ampla para discutir aspectos entre a problematização e sua respectiva estratégia de solução na produção de habitação social na Amazônia.
\end{abstract}

Palavras-chave: Projeto arquitetônico, Habitação Social, Sentido de lar, Amazônia.

\begin{abstract}
It is investigated the production of social housing and the concept home, aiming to raise the sense of home in relocation/resettlement situations in the Amazônia, considering significant and strongly referenced aspects in the physical space, associated to the subjective aspects of living for the inhabitant and complementing the interpretation of the space built under the eyes of the technicians involved in the implementation of the policy on housing resettlement proposed in the Taboquinha Project, Belém-Pará. It was adopted as a methodology, the research of the qualitative type, with a multi-method approach, using the field research with data collection, through the application of questionnaires, visual mapping and interviews with the residents. The results point to the presence of home's sense for the residents when they say they lack something related to subjective aspects, or customs, affective values. As a contribution, the results promote a fruitful discussion among the different actors involved in housing production, supporting itself on a broader basis to discuss aspects between the problematization and its respective strategy of solution in the production of social housing in the Amazônia.
\end{abstract}

Keywords: Architecture project, Social housing, Home sense, Amazônia.

\section{INTRODUÇÃO}

A concepção arquitetônica é um desafio que envolve diversos caminhos para o arquiteto, na busca de atender e relacionar o ser humano com o ambiente construído. No contexto da habitação social, em se tratando de processos de remanejamento/reassentamento habitacional, é importante compreender os

AMPUERO, N. G. S.; PERDIGÃO, A. K. A. V. O sentido de lar na produção da habitação social: estudo no Taboquinha. In: SIMPÓSIO BRASILEIRO DE QUALIDADE DO PROJETO NO AMBIENTE CONSTRUÍDO, 6., 2019, Uberlândia. Anais... Uberlândia: PPGAU/FAUeD/UFU, 2019. p. 1566-1577. DOI https://doi.org/10.14393/sbqp19141. 
valores objetivos e subjetivos do habitar para o atendimento das necessidades humanas. Na produção habitacional, encontram-se aspectos relacionados a interação entre o ser humano e o ambiente construído, que impactam sobremaneira na elaboração do projeto de arquitetura.

A pesquisa delineou-se para a investigação de valores objetivos e subjetivos do habitar, adotando-se o conceito de lar como um conceito amplo e que pode ser explorado por diversas áreas e assim instigando para a contribuição no campo do projeto de arquitetura e, mais, de grande relevância para produção de habitação social.

A subjetividade incide especialmente na ruptura com referências espaciais, por isso, Perdigão e Bruna (2010), destacam o trabalho de Fullilove (1996), cujos estudos psiquiátricos, revelam que processos psicológicos relacionados ao vínculo, à familiaridade e à identidade, são ameaçados por deslocamentos espaciais quando há ruptura com o sentido de lugar pela falta de conexões emocionais, conduzindo a problemas de nostalgia, desorientação e alienação, respectivamente. As necessidades emocionais são destacadas por Camargo (2010), afirmando que o lar não é apenas um espaço que atende as necessidades físicas de um usuário, ele também atende necessidades emocionais. Perdigão e Gayoso (2012) exploram a casa como categoria, como elemento central de aspectos que relacionam objetividade $e$ subjetividade no espaço construído.

Costa, Perdigão e Cavalcante (2015), empregam olhares de vários campos do conhecimento sobre a produção habitacional e adotam adaptação como aquele que demonstra evidências de que as famílias em processo de remanejamento e que se deparam com diferentes tipologias entre a casa de origem e a casa destino, apresentam conflitos e falta de identificação com o espaço habitacional.

Os valores culturais e simbólicos que incorporam relações, necessidades e expectativas dos usuários com o espaço construído podem ser observados em várias escalas. Norbergh-Schulz (2007), Perdigão e Malard (2006), oferecem contribuições ao entendimento do projeto atendendo à dimensão sensível da arquitetura. Contudo, observa-se nos resultados de pesquisas em áreas habitacionais em Belém (PA), que esses valores muitas vezes não são agregados ao projeto arquitetônico em seus diversos métodos e etapas.

A realização de estudos sobre habitação social em áreas de remanejamento/reassentamento, a equipe do Laboratório Espaço e Desenvolvimento Humano (LEDH) da Universidade Federal do Pará, através da pesquisa "O PAC Urbanização de Assentamentos Precários em Cidades Amazônicas: proposta metodológica para avaliação da produção e ocupação humana na política habitacional em Belém e Macapá" realizada pelos Programas de Pós-Graduação da Universidade Federal do Pará em Arquitetura e Urbanismo, em Serviço Social e em Teoria e Pesquisa do Comportamento, tem acumulado importantes contribuições para intervenções futuras. Os resultados de pesquisa e publicações realizadas constataram a existência de problemas com adaptação habitacional, apontando um intenso processo de adaptação na nova unidade habitacional a partir de modificações realizadas pelos moradores, as quais vem ocorrendo sem orientação técnica. Uma área que passa por essa transição e reflete esta problemática é o Projeto Taboquinha, localizado em uma Comunidade 
denominada Cubatão, no Distrito de Icoaraci, no Município de Belém-PA, tornando-se alvo do estudo, cuja pesquisa trabalhou analisando respostas de formulários e entrevistas aplicadas no ano de 2018, aos moradores do Projeto Taboquinha e dois técnicos envolvidos, além de registros gráficos e fotográficos.

Ampliando o escopo das pesquisas sobre habitação social, questiona-se em que medida o sentido de lar está presente no projeto de habitação social, para o morador em situação de remanejamento/reassentamento habitacional? As evidências buscadas direcionaram-se para o sentido de lar estar presente e como se mostra através das adaptações/modificações realizadas pelos moradores nas unidades habitacionais no reassentamento.

Objetiva-se discutir o sentido de lar em situações de remanejamento/reassentamento habitacional na Amazônia, contextualização entre olhar técnico e olhar do morador, verificando em que medida há relevância dos aspectos subjetivos para os moradores e técnicos envolvidos.

\section{O SENTIDO DE LAR NA ELABORAÇÃO DO PROJETO - CONSIDERAÇÕES}

O conceito de lar, conhecido por ser relacionar com a moradia, vem sendo trabalhado por vários autores, de áreas de concentração variadas. Camargo (2010), cita que a casa tem o significado semelhante ao de lar e que não se trata apenas de espaço físico, de estrutura física, existe um contexto subjetivo, a experiência de habitar o espaço físico, ou seja, ela é o local onde se pratica o habitar. Rybczynski (1996), complementa que o interior de um ambiente comunica a personalidade do usuário, os objetos compõem marcas dos donos e a casa passa a ser lar, quando se entende mistérios do conforto e relaciona intimidade, sentidos, bem-estar físico, entre outros fatores.

Segundo Perdigão e Gayoso (2012), sendo um espaço mais "restrito" ou mais "amplo", a casa traz como primeira função, a de habitar, e essa forma de habitar traz na sua forma de uso, inúmeros significados. Norbergh-Schulz (2006, p. 455), define a palavra habitar: "Usamos a palavra "habitar" para nos referirmos as relações entre o homem e o lugar. " A partir desta relação, Camargo (2010), explicita que de acordo com o cotidiano criado na morada, hábitos, costumes, são formados e acompanham o homem para o resto da vida $e$ independente de mudanças, o que foi vivenciado e formado, permanece no inconsciente.

Essa interação entre o homem e o ambiente físico, é importante ser interpretada para analisar as reais necessidades humanas e na elaboração de projetos menos generalistas (PERDIGÃO, OLIVEIRA E MENEZES, 2017). Pinto (1965), afirma que além das necessidades humanas indispensáveis à sobrevivência física, tem-se as de natureza espiritual (necessidades psicológicas, artísticas e ideológicas).

Dessa forma, Ribeiro (2003), cita que o costume em não considerar os significados vinculados a experiências e memórias afetivas das pessoas, dificulta para o arquiteto a elaboração de projetos melhores. A autora também reitera que cabe ao arquiteto promover e facilitar as percepções espaciais, para que as interações do ser humano com o seu meio ambiente satisfaçam todos os sentidos. 
Referindo-se a projetar, é um tema importante que merece ser discutido, ainda mais em um mundo em constante transformação. Malard (2005), cita que independente da complexidade de um projeto de arquitetura, ele implica na necessidade de um processo de pesquisa.

Esse processo requer conhecimento sólido na área de atuação e base crítica, para não mecanizar, além de que deve considerar as sensações fisiológicas e psicológicas dos usuários (BARROS E PINA, 2010).

Del Rio (1998), contribui afirmando que a elaboração do projeto depende tanto da nossa criatividade, quanto da nossa capacidade de síntese, abstração, criação e representação. O autor também informa que nos caminhos pessoais do ensino e da metodologia, o arquiteto deve atuar inserido nas especificidades dos contextos, atendendo a sua responsabilidade social, fazendo com que o paradigma social se some ao artístico e ao tecnológico, voltando o processo de projeto as reais necessidades dos usuários, comportamento, percepção, expectativas. Malard (2005), relata que o conhecimento e análise de dados são uma etapa indispensável ao processo de criação para a atividade projetual.

Portanto, a percepção arquitetônica de fatores que influenciam na relação ambiente-comportamento, são essenciais ao processo de projeto, no objetivo de harmonia entre anseios de uma comunidade e qualidades do local (BARROS E PINA, 2010).

\section{PESQUISA EM ÁREA DE REASSENTAMENTO HABITACIONAL NO PROJETO TABOQUINHA}

Trata-se de uma pesquisa exploratória, do tipo qualitativa, com abordagem multimétodos. A realidade empírica investigada refere-se às unidades habitacionais ao Projeto Taboquinha com a previsão de urbanização e de remanejamento/reassentamento de várias famílias, onde tem-se a construção de unidades habitacionais térreas e sobrados (Figura 1). O Projeto teve a intervenção do Ministério Público do Pará, que segundo a Promotoria de Justiça do Distrito de Icoaraci, ocorreu devido reclamações dos moradores que se encontravam insatisfeitos com a gestão e execução do mesmo.

O Projeto teve início com uma demanda de uma área de ocupação informal, com habitações em sua maioria de tipologia palafita denominada Comunidade Cubatão, localizada em Icoaraci/PA. Essa Comunidade faz parte de um assentamento precário e tem a presença de um igarapé denominado Tabocal. O Projeto Taboquinha, localiza-se na Comunidade Cubatão, área de proteção ambiental e de propriedade da marinha, que foi delimitado pelas ruas 15 de Agosto, Cruzeiro, 2 de Dezembro e Travessa Pimenta Bueno (Figura 2) e que ao longo do desenvolvimento do Projeto, houveram ampliações.

As primeiras unidades habitacionais foram entregues em 2010 (COHAB, 2010). De acordo com a equipe técnica da Companhia de Habitação do Estado do Pará (Cohab), o Projeto encontrava-se em fase final, no ano de 2018, com $82,43 \%$ de obra concluída (habitação e infraestrutura) e $95 \%$ de remanejamento concluído. 


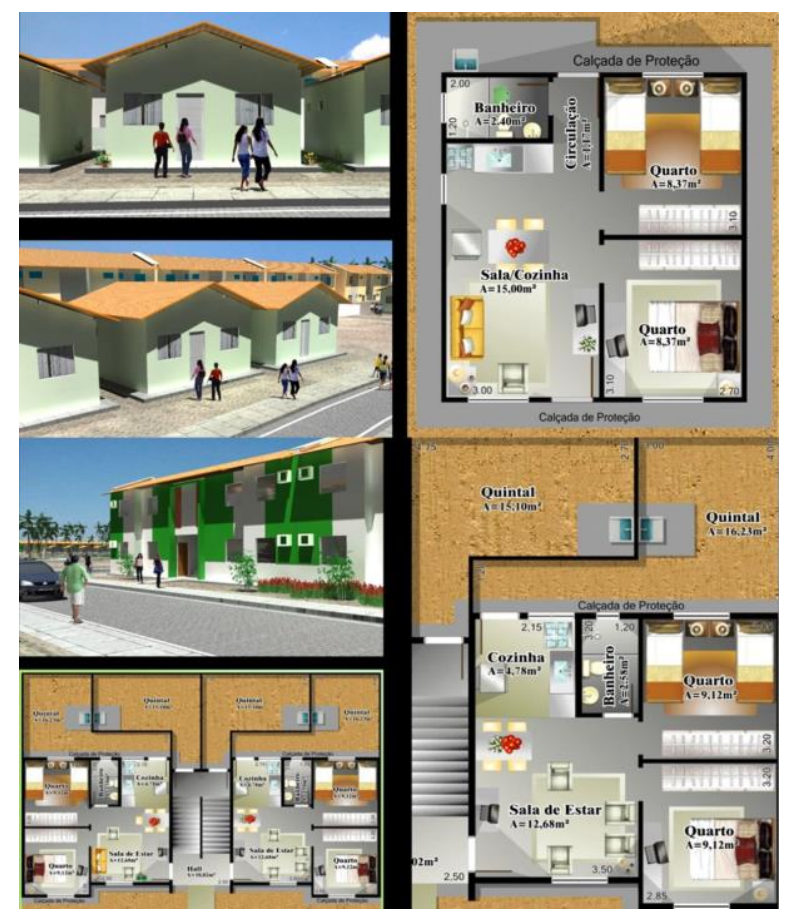

Figura 1 - Unidades habitacionais do Projeto Taboquinha Fonte: COHAB (2010)

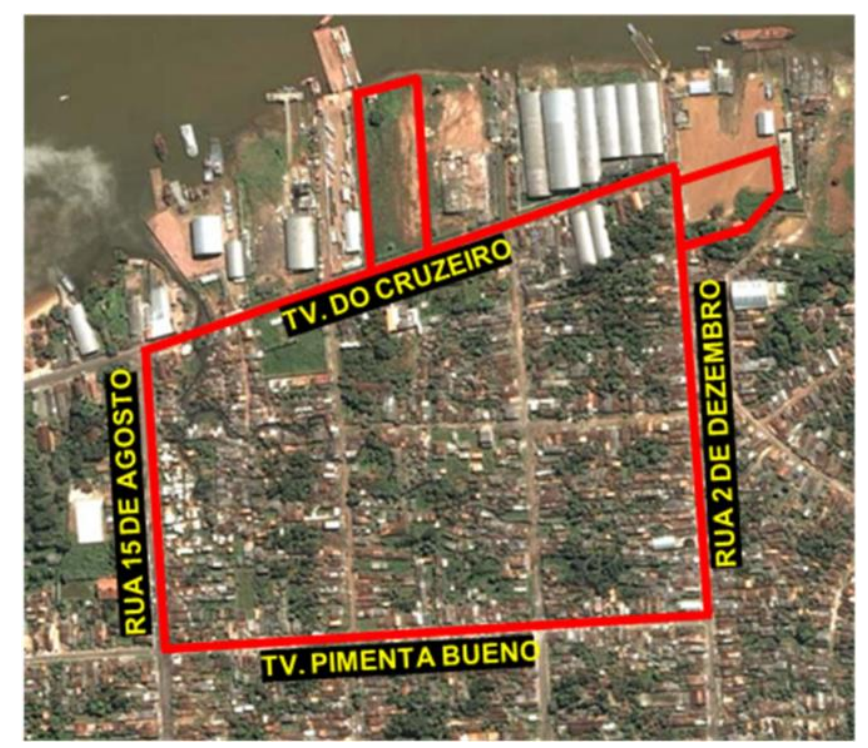

Figura 2 - Área da poligonal do Projeto Taboquinha Fonte: COHAB (2010)

A pesquisa sobre o sentido de lar na produção de habitação social adotou um trabalho de campo com adoção de várias técnicas de pesquisa para consulta aos moradores que passaram pelo processo de remanejamento/reassentamento do Projeto Taboquinha. A consulta ao técnico de arquitetura da Cohab e ao técnico do Ministério Público-PA se deu através de entrevista presencial. Nos dois casos, o interesse é o de capturar a interpretação sobre o sentido de lar em suas respostas. 
Foram aplicadas três técnicas de pesquisa, com seis moradores do Projeto Taboquinha que pertenceram a área de ocupação informal, sendo complementadas com registros gráficos e fotográficos nas unidades habitacionais, além disso, as entrevistas com os técnicos citados (técnico de arquitetura da Cohab e técnico jurídico do Ministério Público-PA).

Em relação as técnicas, o Formulário de Adaptação Habitacional é um instrumento elaborado pela equipe do Projeto "O PAC Urbanização de Assentamentos Precários em Cidades Amazônicas: proposta metodológica para avaliação da produção e ocupação humana na política habitacional em Belém e Macapá", que consta de diversas perguntas relacionadas a casa e a relação do morador com a mesma. A Consulta não verbal sobre a Temporalidade do Habitar, é um instrumento elaborado por Perdigão (2006), constando perguntas relacionadas a experiências do habitar do usuário. 0 Mapeamento Visual, trata-se de um instrumento elaborado por Thorne (1995), onde, através de plantas baixas de ambientes que se deseja examinar, juntamente com questões para estimular o usuário, avalia-se graficamente pontos positivos e negativos. As entrevistas foram realizadas com perguntas a respeito da participação dos entrevistados no Projeto Taboquinha, como o Projeto Taboquinha e o Projeto de arquitetura interferem para o morador, o que se entender por sentido de lar e repercussões.

\section{APRESENTAÇÃO E DISCUSSÃO DOS RESULTADOS}

Apresentam-se os resultados de pesquisa no Quadro 1, referentes ao Formulário de Adaptação Habitacional, onde evidenciaram a presença do sentido de lar através de perguntas que relacionam a casa atual e a casa anterior e que se manifesta no espaço físico através de modificações demonstrando as tentativas de identificação com a casa. Constata-se que a casa para onde foram remanejados, recebeu pontos positivos, porém, em sua maioria, após a possibilidade de alterações, demonstravam a necessidade de adaptação. Além disso, tiveram respostas relacionadas a aspectos imateriais, a sensações, colocadas como importantes para os moradores consultados.

\section{Quadro 1 - Respostas dos moradores quanto as casas}

\begin{tabular}{|c|c|c|c|}
\hline Moradores & Casa anterior & Casa atual & Sente falta de algo \\
\hline 1 & $\begin{array}{l}\text { "Cozinha, tinha } \\
\text { espaço, era grande" }\end{array}$ & $\begin{array}{l}\text { "Melhorou porque tem } \\
\text { saneamento" }\end{array}$ & $\begin{array}{c}\text { "Mais espaço para fazer } \\
\text { minhas coisas" }\end{array}$ \\
\hline 2 & "Era fria, confortável" & $\begin{array}{l}\text { "Deixo assim, gosto mais da } \\
\text { rua, gostava da outra que } \\
\text { era na beira do igarapé" }\end{array}$ & $\begin{array}{l}\text { "De uma área aberta, da } \\
\text { beira do rio, gostava" }\end{array}$ \\
\hline 3 & $\begin{array}{c}\text { "Gostava de tudo, } \\
\text { casa não tinha muitos } \\
\text { cômodos, mas pátio e } \\
\text { cozinha grandes" }\end{array}$ & $\begin{array}{l}\text { "Gosto também, melhorou, } \\
\text { aumentei o espaço" }\end{array}$ & $\begin{array}{l}\text { "Não sinto falta, porque } \\
\text { estou modificando" }\end{array}$ \\
\hline 4 & $\begin{array}{c}\text { "Gostava, tinha um } \\
\text { bar" }\end{array}$ & $\begin{array}{l}\text { "Área do bar que pude } \\
\text { construir também" }\end{array}$ & $\begin{array}{l}\text { "Não, porque fiz meu bar, } \\
\text { aumentei a cozinha" }\end{array}$ \\
\hline 5 & "Família reunida" & "Silêncio" & $\begin{array}{l}\text { "Espaço para criança } \\
\text { brincar. Casa maior" }\end{array}$ \\
\hline 6 & $\begin{array}{l}\text { "Era linda, toda em } \\
\text { madeira" }\end{array}$ & $\begin{array}{l}\text { "Não gosto, não me } \\
\text { agrada" }\end{array}$ & $\begin{array}{c}\text { "Tudo, amava minha casa } \\
\text { anterior" }\end{array}$ \\
\hline
\end{tabular}

Fonte: pesquisa de campo 2018 
As respostas (Figura 3) da Consulta não verbal sobre a Temporalidade do Habitar, confirmaram a existência de uma relação que fica na memória e que de algum modo busca correspondência no espaço habitacional. Os resultados levam a constatação do papel do sentido de lar e que faz parte do crescimento e formação do ser humano, intervindo na maneira como se relaciona com a moradia. Esses fatos são constatados em respostas com lembranças ligadas a questões não estruturais, como a família, respostas que fazem referência a recordações do passado, como uma festividade, ou um desejo para a casa atual, que tenha valor afetivo, como morar na beira de um rio, ou seja, valores subjetivos evidentes nas respostas, que os moradores buscam ou pretendem suprir com a moradia atual.

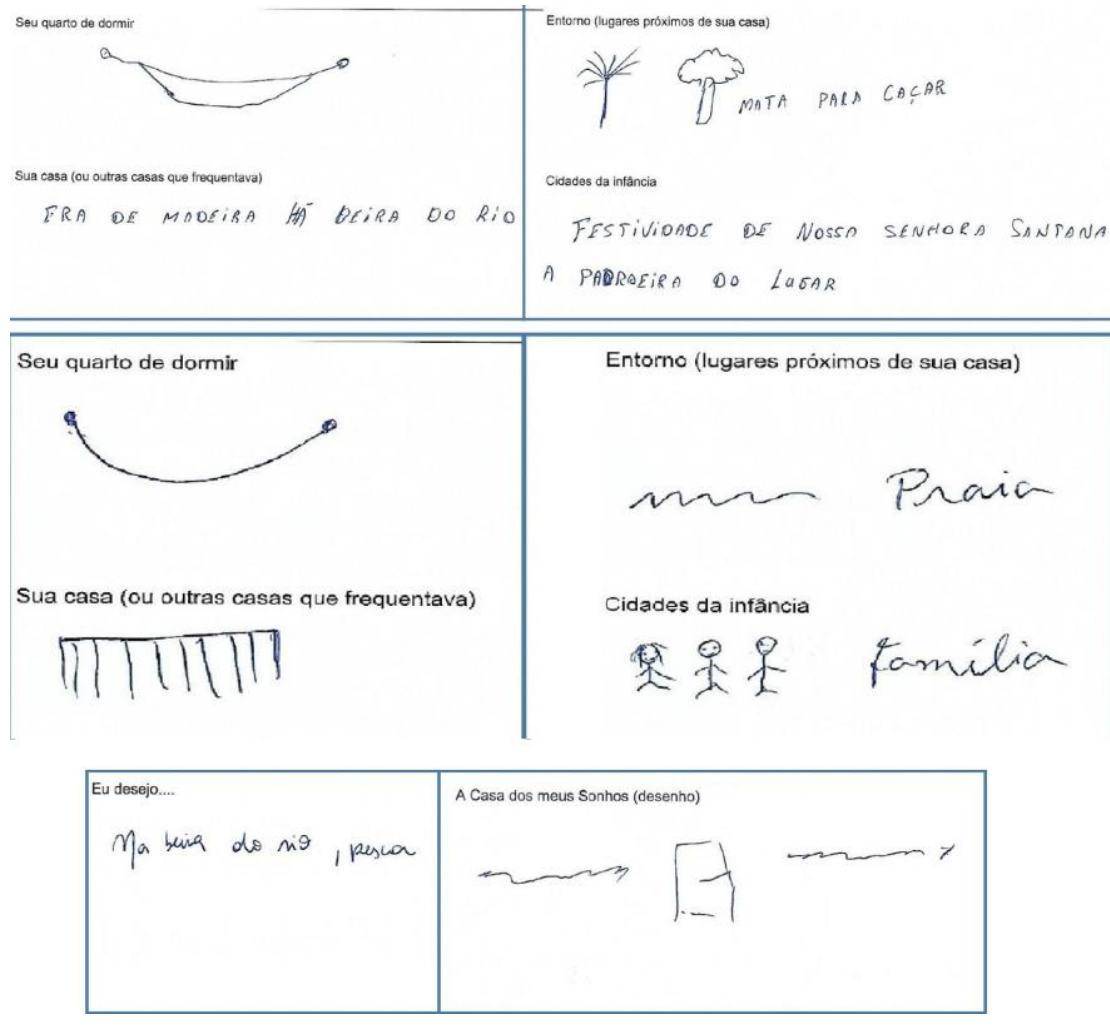

Figura 3 - Síntese das respostas da Consulta não verbal sobre a Temporalidade do Habitar

Fonte: Pesquisa de campo (2018)

Através da técnica de Mapeamento Visual (Figura 4) e com apoio dos registros gráficos e fotográficos (Figura 5 e Figura 6), observa-se a quantidade de modificações realizadas para adaptação do morador ao novo espaço habitacional. Contudo, as alterações, além do atendimento do espaço nas novas edificações, para com os anseios e necessidades dos moradores, aparecem também conflitos pelas modificações realizadas, gerando impasses por conta de construção de lajes, ocupações de áreas abertas, como quintais, que também têm importância para o usuário, mas que não encontraram outra alternativa pela falta de áreas disponíveis para expansão, mesmo nas unidades térreas. Destaca-se também um caso interessante, onde uma casa não foi alterada pelo fato de aspectos físicos não serem os mais importantes, segundo o entrevistado, reforçando também os resultados das 
técnicas anteriores, quando afirmam que sentem falta de algo de valor afetivo, de um costume referente a casa anterior.

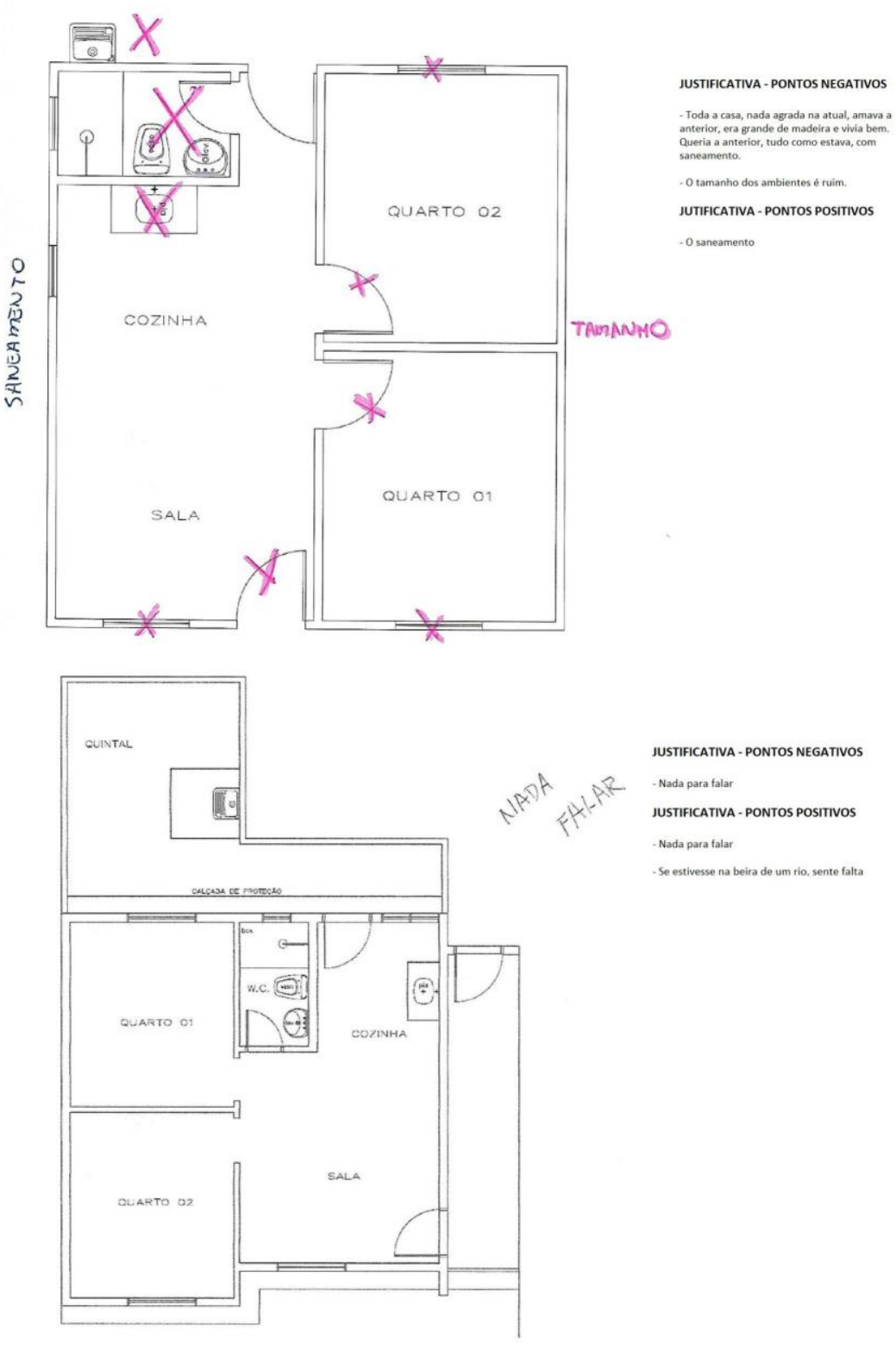

Figura 4 - Formulários de Mapeamento Visual Fonte: Pesquisa de campo (2018)

Mostra-se na Figura 5, a construção de laje em área livre, ampliação da frente de uma unidade térrea, para construção de um bar e ampliação da casa em área de quintal.
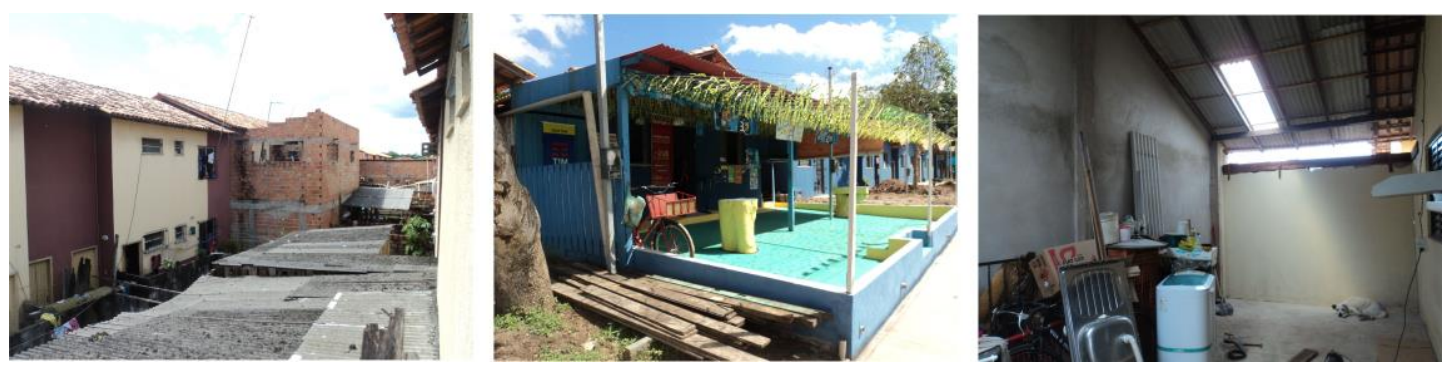

Figura 5 - Habitações modificadas 


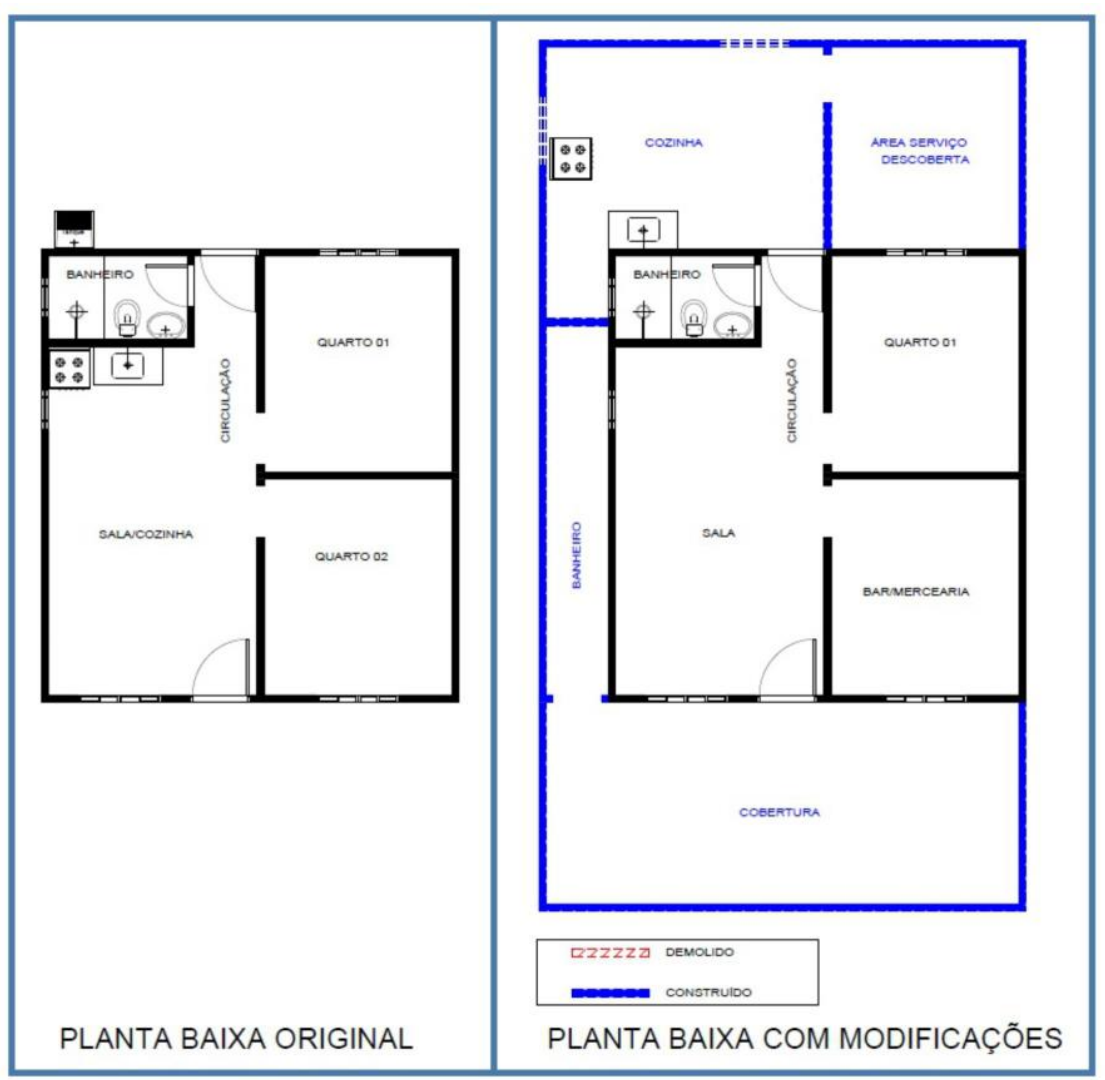

Figura 6 - Planta baixa de uma casa modificada do Projeto Taboquinha Fonte: Pesquisa de campo (2018)

Quanto as entrevistas com o técnico de Arquitetura da COHAB e o técnico jurídico do Ministério Público-PA, os resultados mostraram que ambos têm a compreensão do sentido de lar e que esse sentido também é fundamental para o ser humano habitar uma casa, porém, em específico ao técnico de arquitetura, não dá a mesma consideração que demonstra por aspectos geométricos e funcionais. O técnico jurídico demonstrou não atentar para essa importância, mas sabe que o lado humano contribui para melhorar os processos de remanejamento/reassentamento habitacionais. Segue o Quadro 2 com a síntese das respostas dos técnicos.

\section{Quadro 2 - Síntese das entrevistas com os técnicos}

\begin{tabular}{|c|c|}
\hline Técnicos & Respostas \\
\hline $\begin{array}{c}\text { Técnico de } \\
\text { Arquitetura da Cohab }\end{array}$ & $\begin{array}{c}\text { "Eu acho que sim, que o projeto apresenta repercussões no usuário, } \\
\text { além das funcionais, mas eles não enxergam que estão em uma casa } \\
\text { de madeira, sem tratamento" } \\
\text { "Melhora sim as condições deles, pois saem de uma condição ruim de } \\
\text { habitação, para uma condição melhor de habitação" } \\
\text { "O imóvel só é lar, quando aquela família se propõe a manter uma } \\
\text { unidade...porque tem um ambiente de convivência entre eles" } \\
\text { "Tem que entender como é a vivência deles...particularidades, a gente } \\
\text { precisa enxergar" }\end{array}$ \\
\hline $\begin{array}{c}\text { Técnico jurídico do } \\
\text { Ministério Público }\end{array}$ & $\begin{array}{c}\text { "Eu particularmente não atentei para isso" (necessidades não-físicas, } \\
\text { em processos de remanejamento/reassentamento) } \\
\text { "Entendo que o projeto de arquitetura apresenta repercussões no }\end{array}$ \\
\hline
\end{tabular}


\begin{tabular}{|l|c|}
\hline & $\begin{array}{c}\text { usuário além de físicas e funcionais, que reflete na auto-estima" } \\
\text { "O lar é união, paz, amor, tranquilidade, onde você repousa" }\end{array}$ \\
\hline
\end{tabular}

Fonte: pesquisa de campo 2018

Através dos instrumentos aplicados, constatou-se o quanto se manifesta 0 sentido de lar, que eles se complementaram e o confirmaram mais ainda, visto que respostas de um instrumento, reforçavam respostas do outro, algo muito interessante identificado ao aplicar três técnicas com cada morador. Essa manifestação do sentido de lar se dá em diversos pontos, na satisfação dos moradores quanto ao bem-estar na moradia, nos vínculos que eles costumam manter, relacionados a experiências do passado e também diversas modificações realizadas nas casas atuais que se alinham com casa anteriores, ou na busca de retomar e/ou manter hábitos.

\section{CONCLUSÃO}

Através dos resultados com as técnicas aplicadas, o sentido de lar se mostra pelos moradores do Projeto Taboquinha, através das adaptações realizadas nas habitações como uma tentativa de resgatar algumas relações e referências que foram rompidas no processo de remanejamento/reassentamento. Dessa forma observa-se a clara relação entre elementos físicos e os vínculos estabelecidos com o espaço, demonstrando a relevância dos valores subjetivos do habitar. Por outro lado, o sentido de lar como resposta dos técnicos consultados, mostra-se sem a importância manifestada pelos moradores.

Com os resultados e discussão da pesquisa, o sentido de lar se mostrou fundamental ao morador pertencente ao Projeto Taboquinha, influenciando significativamente para a edificação que habita ou que venha a habitar, propiciando interações positivas com a casa, quando observadas sensações, tradições, valores afetivos do usuário.

A investigação trouxe a discussão do sentido de lar e partes levantadas para indicações para elaboração de projetos com mais qualidade para o morador em programas habitacionais em situação de remanejamento/reassentamento habitacional, para compreensão dos valores humanos para a pessoa. Ressalta-se a importância da arquitetura para oferecer mais qualidade ao usuário final em projetos de habitação social, quando os resultados encontrados demonstram o quanto o morador necessita buscar soluções próprias para adaptação ao novo espaço habitacional.

A metodologia evidenciou que o sentido de lar é resgatado ou tenta ser resgatado, pelo dimensionamento do espaço e que a relação com a moradia vai além de relações físico-espaciais e está presente em evidências de manutenção de costumes, gostos, além disso, evidenciou-se a busca por adaptações através das modificações realizadas no intuito de se adequar à nova moradia e diminuir referências espaciais rompidas, como também, as relações em casas anteriores e/ou entorno que fizeram parte da vida do usuário, mostrando o não atendimento as necessidades e aspirações do morador que ultrapassam a esfera física. As entrevistas com os técnicos, constatam também a pouca consideração dos valores subjetivos, comparados a valores físicos, questões estruturais.

Estudos de aspectos mais abrangentes sobre a casa, físicos e não físicos, para incorporação à atividade projetual, inclusive o que e quais são esses valores 
para o morador, vem se mostrando de grande importância para um projeto arquitetônico mais coerente com o modo de vida do usuário, especialmente em processos de remanejamento/reassentamento habitacional e assim diminuir as dificuldades e problemas encontrados na adaptação habitacional.

O sentido de lar, do ponto de vista do arquiteto, incorpora-se desde o processo de projeto, através de projetos mais humanizados. A disseminação de aspectos objetivos e subjetivos do habitar é importante como subsídio técnico, passando não só por equipe de projeto e construção, como social e jurídica. Desta maneira, torna-se de grande importância na obtenção de uma melhor concepção de projeto arquitetônico, nos resultados de processos de remanejamento/reassentamento habitacional, como é o caso da produção habitacional na Amazônia, oferecendo um espaço habitacional mais condizente com seu modo de vida, além de mostrar a importância da relação entre ensino, pesquisa e prática.

\section{REFERÊNCIAS}

CAMARGO, E. N. Casa, doce lar: O habitar doméstico percebido e vivenciado. São Paulo. Editora: Annablume, 2010.

BARROS, R. R. M. P.; PINA, S. A. M. G. Uma abordagem de inspiração humanizadora para o projeto de habitação coletiva mais sustentável.

Ambiente Construído, Porto Alegre, v. 10, n. 3, p. 121-135, jul/set. 2010.

$\mathrm{COHAB}, \mathrm{PA}, \mathrm{Companhia} \mathrm{de} \mathrm{habitação} \mathrm{do} \mathrm{Pará.} \mathrm{Plano} \mathrm{de} \mathrm{remanejamento}$

Comunidade Taboquinha. Belém, 2010.

COSTA, S. M. G.; PERDIGÃO, A. K. A. V.; CAVALCANTE, L. I. C. Política

habitacional em Belém (PA): estudo sobre adaptação habitacional em

tipologias multifamiliares. Argumentum, Vitória (ES), v. 7, n. 2, p. 302-317, jul/dez. 2015.

DEL RIO, V. Projeto de Arquitetura: entre criatividade e método. In: DEL RIO, V. (Org.) Arquitetura: pesquisa e projeto. São Paulo: ProEditores; Rio de Janeiro: FAU/UFRJ, 1998.

MALARD, M. L. As aparências em Arquitetura. Belo Horizonte: Editora UFMG, 2006.

MALARD, M. L. Cinco textos sobre arquitetura. Belo Horizonte: Editora UFMG, 2005.

NORBERGH-SCHULZ, C. A arquitetura como espaço existencial. In: MONTANER, J. M. Arquitetura e Crítica. Barcelona: Editora Gustavo Gili, 2007.

NORBERGH-SCHULZ, C. O Fenômeno do lugar. In: NESBITT, K. (Org). Uma nova agenda para a Arquitetura. Antologia teórica 1965-1995. São Paulo: Cosac Naify, 2006.

PERDIGÃO, A. K. A. V.; OLIVEIRA, L. F.; MENEZES, T. M. S. O modo de habitar amazônico: os conflitos espaciais entre a produção informal e a produção formal de moradia na Vila da Barca, Belém, Pará, Brasil. In: $4^{\circ} \mathrm{CIHEL} \mathrm{-}$ Congresso Internacional da Habitação no Espaço Lusófono. A cidade habitada. Portugal: Universidade Beira Interior, 2017.

PERDIGÃO, A. K. A. V.; GAYOSO, S. Interpretações sobre a Casa para Produção de Moradia. In: SANTANA, J. V.; HOLANDA, A. C. G.; MOURA, A. (Org). A 
questão da habitação em municípios Periurbanos na Amazônia. Belém: Edufpa, 2012. P. 113-131.

PERDIGÃO, A. K. A. V.; BRUNA, G. C. O papel do projeto de arquitetura na produção da moradia. In:PPLA 2010: SEMINÁRIO POLÍTICA E PLANEJAMENTO, 2, 2010. Curitiba: Ambiens, 2010.

PERDIGÃO, A. K. A. V. A dimensão afetiva da arquitetura de espaços habitacionais. São Paulo, SP: USP, 2006. Tese de doutorado, Universidade de São Paulo, 2006.

PINTO, A. A. Valores arquitetônicos. 1965. 88 f. Dissertação (Mestrado em Arquitetura e Urbanismo), Universidade de Brasília, Brasília, 1965.

RIBEIRO, C. R. V. A dimensão simbólica na Arquitetura: Parâmetros intangíveis do espaço concreto. Belo Horizonte: C/Arte, 2003.

RYBCZYNSKI, W. Casa, pequena história de uma ideia. São Paulo: Editora Record, 1996.

THORNE, R. Using Visual Methods to Focus User's Response in Predesign and Post-occupancy Research. In: BAIRD, G. et al. (Edit). Building Evaluation Techniques. New York: McGraw-Hill, 1995, p. 123-128. 